\title{
ATENÇÃO FARMACÊUTICA NA DROGARIA
}

\author{
Débora Paula Loureiro Bragança Milioli ${ }^{1}$ \\ Thiago Pereira de Abreu ${ }^{2}$
}

RESUMO: Esse artigo apresenta as atividades desenvolvidas pelo farmacêutico em uma Drogaria , abordando desde as suas responsabilidades técnicas, burocráticas como sua atuação com a atenção farmacêutica voltada ao paciente. Esse projeto visa a interface entre pesquisa, ensino e extensão na minha área que é a de farmacêutica , bem como orientar aos pacientes quanto ao uso racional dos medicamentos a fim de promover a saúde dos mesmos e a desmistificação de que a Drogaria só seria um estabelecimento comercial, mas como também um ambiente onde sempre terá um profissional voltado a esclarecer dúvidas e dar todas as orientações adequadas aos pacientes. O farmacêutico responsável sempre supervisiona os balconistas ,se for necessário o mesmo interfere no atendimento para correções e esclarecimento da prescrição médica e dúvidas medicamentosas.

Palavra-Chave: Farmacêutico. Atenção farmacêutica. Atuação do farmacêutico. Profissão farmacêutica. Drogaria.

SUMMARY: This article presents the activities carried out by the pharmacist in a drugstore, approaching from his technical and bureaucratic responsibilities as well as his performance with pharmaceutical care focused on the patient. This project aims at the interface between research, teaching and extension in my area which is pharmaceutical, as well as guiding patients on the rational use of medicines in order to promote their health and the demystification that the drugstore would only be a commercial establishment, but also an environment where there will always be a professional dedicated to clarifying doubts and giving all the appropriate guidance to patients. The responsible pharmacist always supervises the clerks, if necessary, he interferes in the service for corrections and clarification of medical prescription and medication questions.

Keyword: Pharmaceutical. Pharmaceutical attencion. Pharmacist`s performance. Pharmaceutical profession. Drugstore.

\section{INTRODUÇÃO}

\footnotetext{
I Gradução em farmácia pela Universidade UNIG.

${ }^{2}$ Doutorado em Ciências Biológicas. Orientador.
} 
O Farmacêutico é um profissional perito no uso de medicamentos e fármacos, bem como as suas conseqüências no organismo humano. É um profissional da saúde obcecado por conhecimento científico e consciente de suas responsabilidades sociais, é alguém que luta para que a sociedade tenha acesso aos medicamentos e aos seus serviços, por entender o quanto é importante o seu papel para o bem estar das pessoas. Cabe a ele a responsabilidade de proteger a sociedade dos efeitos colaterais dos medicamentos que quando usados de maneira errada, podem transformar-se em um tóxico letal ou simplesmente não atingir o efeito esperado.

O farmacêutico deve representar a Drogaria em todos os aspectos técnicos científicos e responder por todos os atos praticados, executados por ele ou não. As atribuições do farmacêutico técnico responsável pelo estabelecimento são as clínicas e não clínicas.

Atribuições não clínicas:

- Monitoramento e aquisições de estoque;

- Intercambialidade de medicamentos;

- Elaboração do Plano de Gerenciamento de Resíduos de Serviços de Saúde(PGRSS);

- Atualização de documentação legal;

- Elaboração do Manual de Boas Práticas de Dispensação;

- Elaboração dos Procedimentos Operacionais Padrão (POPs);

- Uso de ferramentas administrativas e financeiras, como escrituração de medicamentos no Sistema Nacional de Gerenciamento de Produtos Controlados (SNGPC)

Atribuições clínicas ( de acordo com a Resolução do Conselho Federal de Farmácia CFF - 565):

- Estabelecer e conduzir uma relação de cuidado centrada no paciente;

- Participar do planejamento e da avaliação da farmacoterapia, para que o paciente use de maneira segura os medicamentos de que necessita, em doses, freqüências, horários, vias de administração e duração; 
- Analisar a prescrição medicamentosa;

- Prover a consulta farmacêutica em consultório ou ambiente adequado;

- Identificar, avaliar e intervir nas interações medicamentosas indesejadas.

Dentre todas essas atuações, um dos campos de atuação de suma importância é a Atenção Farmacêutica ao paciente no balcão da Drogaria, que trata-se de um conceito no qual o paciente é o principal beneficiário, o profissional interage diretamente com os pacientes para atender suas necessidades relacionadas aos medicamentos.

Os farmacêuticos que atuam em Drogarias, são os últimos profissionais da saúde a manter contato com os pacientes. Os seus serviços são um muro de proteção à sociedade contra os problemas quanto ao uso de medicamentos, que por mais inofensivo que aparenta ser, pode desencadear sérias reações indesejáveis.

Um fator que dificulta a Atenção Farmacêutica ao paciente é a falta de uma área privativa para atendimento. Também há todo o conjunto de atividades administrativas e burocráticas que consomem grande parte do tempo de trabalho limitando a dedicação desse profissional ao paciente.

Todas as ações da assistência farmacêutica têm como foco o uso racional do medicamento. Atualmente a maioria da população convive com pelo menos um problema de saúde, o que muitas vezes necessita de medicação, por isso o farmacêutico é fundamental, uma vez que o paciente necessita de cuidados e atenção.

\section{OBJETIVO GERAL}

O objetivo geral desse trabalho é refletir sobre o perfil do farmacêutico onde atuam e a dinâmica de trabalho que possuem. De se avaliar a importância de se ter um profissional farmacêutico na Drogaria, orientando os funcionários quanto ao cuidado no atendimento e dispensação adequada quanto na forma farmacêutica, doses e período de duração do tratamento a um preço acessível e de como sua atenção no balcão da Drogaria faz a diferença na rotina do paciente e sua segurança quanto ao uso racional do medicamento. 


\section{OBJETIVO ESPECÍFICO}

- Avaliar se a atenção farmacêutica está sendo feita de forma adequada nas Drogarias;

- Descrever a importância do farmacêutico na farmácia clínica e na atenção farmacêutica;

- Participar junto ao paciente da elaboração de um plano de cuidado;

- Orientar sobre o uso racional do medicamento;

- Avaliar o conhecimento do paciente à respeito das informações técnicas do medicamento a ser utilizado.

\section{METODOLOGIA}

Para o desenvolvimento desse estudo, foram realizadas diversas pesquisas baseadas em artigos, revistas eletrônicas, base de dados como SCIELO, Google Acadêmico e sites oficiais como da Vigilância Sanitária e do CFF. Trata-se de um estudo que tem por objetivo abordar aspectos sobre a importância do farmacêutico no âmbito de uma Drogaria.

Os estudos analisados compreendem ao período de 2009 à 2021.

\section{JUSTIFICATIVA}

A abordagem desse tema se dá por ter a necessidade de conhecer e aprofundar-se sobre a atuação do farmacêutico dentro de uma Drogaria, desde as suas responsabilidades técnicas até a atenção farmacêutica que se faz no balcão da mesma aos pacientes.

Percebe-se que ainda existem algumas dificuldades por parte desse profissional em relação a atenção farmacêutica, por não ter um espaço adequado para isso e por realizarem a farmácia não clínica, qu é a parte burocrática, o que consome a maior parte de seu tempo de trabalho.

A presença do profissional farmacêutico em uma Drogaria é de suma importância para a população em geral, pois a Drogaria deixou de ser somente um 
estabelecimento comercial e passou a ser um local onde se promove saúde e com a orientação farmacêutica par o combate ao uso irracional de medicamento.

\section{DESENVOLVIMENTO}

De acordo com a Organização Mundial da Saúde (OMS), existe uso racional de medicamento, quando os pacientes recebem os medicamentos de acordo com a sua condição clínica e em doses e períodos adequados e ao menor custo possível para cada paciente.

O farmacêutico mais do que nunca tem um papel importante junto a Construção de um novo modelo de atenção à saúde, onde ele possa estar inserido como profissional do medicamento, atuando como referência na orientação, cumprimento, acompanhamento da terapia farmacológica.

Abaixo serão listadas algumas das atribuições burocráticas do dia a dia de um farmacêutico em uma Drogaria:

- O farmacêutico precisa estar cadastrado junto à ANVISA e CRF e cabe a ele conferir e lançar receitas de antibióticos e psicotrópicos no SNGPC ( Sistema Nacional de Gerenciamento de Produtos Controlados);

- Só o farmacêutico poderá fazer a dispensação de medicamentos psicotrópicos e antibióticos, fazendo a conferência junto ao receituário e assinando o mesmo;

- O farmacêutico deve conhecer todos os documentos necessários para o funcionamento regular do estabelecimento, permanecendo com os mesmos em local visível. Estes documentos precisam estar atualizados, em vias originais , que são eles:

- Laudo de Inspeção do Corpo de Bombeiros;

- CNPJ;

- Inscrição Estadual;

- Autorização de Funcionamento de Empresa (AFE) emitida pela ANVISA;

- Certificado de Regularidade Técnica (CRT) emitido pelo CRF;

- Alvará de Saúde emitido pela prefeitura. 
A responsabilidade técnica é uma atividade assumida na empresa ou estabelecimento farmacêutico perante o Conselho Regional de Farmácia (CRF) da jurisdição e os órgãos de vigilância sanitária. $O$ farmacêutico responsável técnico tem responsabilidade de realizar, supervisionar e coordenar todos os serviços técnicoscientíficos do estabecimento (CFF, 2013 a).

É importante também sinalizar que a oferta de treinamento aos profissionais é preconizada pela legislação da Agência Nacional de Vigilância Sanitária (ANVISA), na Resolução da Diretoria Colegiada - RDC nº 44 .

Ressaltado por Paiva e Brandão (2014), os proprietários de Drogarias e os farmacêuticos, responsáveis técnicos por tais estabelecimentos, demonstram certo temor em relação à fiscalização dos órgãos reguladores do Estado, especialmente após a publicação da RDC nº 44/2009 e da legislação referente ao controle de vendas dos antimicrobianos a partir de 2010.

Bastos e Caetano (2010) apontam que as práticas farmacêuticas, estabelecidas pelo modelo tradicional, voltam-se fundamentalmente para os cuidados com o medicamento. Em decorrência disso, estas práticas mostram-se pouco efetivas no controle da morbimortalidade relacionada aos fármacos, o que tem estimulado o surgimento de novas propostas de atuação profissional para o farmacêutico. Destarte, a atenção farmacêutica se apresenta como uma alternativa com o objetivo de redirecionar o trabalho do farmacêutico para os indivíduos, buscando melhora a segurança e efetividade na utilização de medicamentos pela população.

Os estabelecimentos farmacêuticos necessitam reestruturar-se para serem prestadores de assistência e atenção farmacêutica, tal como definido na Política Nacional de Medicamentos (Brasil, 200I).Nesse sentido, as decisões da $\mathrm{I}^{\mathrm{a}}$ Conferência Nacional de Medicamentos e Assistência Farmacêutica, realizada em Brasília, em 2005, reafirmam as novas premissas de formação e do perfil do egresso em farmácia. Após as Conferências as novas Diretrizes Curriculares Nacionais (DCN) dos cursos de graduação em farmácia se voltaram para a formação de profissionais socialmente comprometidos com a garantia do acesso aos medicamentos. 
Para Vieira(2007), a reorientação dos serviços de farmácia passa por diversas ações, dentre elas: implantar ações de atenção farmacêutica para aumentar a aderência ao tratamento; prevenir intoxicações; promover o uso e o armazenamento de forma segura; prevenir o surgimento de problemas relacionados aos medicamentos; capacitar funcionários da Drogaria; integrar farmacêutico e equipe, e a Drogaria aos demais serviços de saúde; elaborar educação em saúde e campanhas vinculadas às necessidades da comunidade ; e melhorar a qualidade da comunicação com o paciente.

Busca-se efetiva implementação do que foi definido na Lei no 5.991/1973(Brasil, 1973), que rege o comércio de medicamentos no país, ou seja, que farmácias e drogarias têm que "contar com a assistência de técnico-responsável, inscrito no Conselho Regional de Farmácia, na forma da lei” e a “ presença do técnico responsável será obrigatória durante todo o horário de funcionamento do estabelecimento".

Portanto, segundo a legislação, sem a supervisão do farmacêutico não pode haver dispensação de medicamentos, uma vez que a mesma é privativa deste profissional. Embora a contribuição do farmacêutico no controle sobre a utilização de medicamentos não se limite à dispensação, sua intervenção eficaz na farmacoterapia, mesmo durante a dispensação, pode minimizar o surgimento de problemas relacionados ao uso de medicamentos (Correr;Pontarolo;Ribeiro,2013).

\section{CONCLUSÃO}

Pode-se concluir nesse estudo, que a atuação do farmacêutico na atenção aos pacientes, pode diminuir o uso irracional de medicamentos evitando possíveis interações medicamentosas, além de proporcionar informações sobre a posologia e forma de armazenamento desses medicamentos.

Com as ações propostas, busca-se também que o paciente mude suas visões quanto à drogaria, não recomendando-a somente com estabelecimento comercial, mas também como um lugar que oferece saúde e orientações corretas sobre medicamentos. 


\section{REFERÊNCIAS BIBLIOGRÁFICAS}

ANGONESE. D.; SEVAlHO, G. Atenção Farmacêutica : fundamentação conceitual e crítica para uma modelo brasileiro. Ciência \& Saúde Coletiva, Rio de Janeiro,v. 15,p.3603-3614, 2010.Suplemento 3.

ANVISA - AGÊNCIA NACIONAL DE VIGILÃNCIA SANITÁRIA. Resolução $\mathrm{RDC}_{\mathrm{n}}{ }^{\mathrm{o}}$ 44, de 17 de agosto de 2009. Dispões sobre Boas Práticas Farmacêuticas para o controle sanitário do funcionamento, da dispensação e da comercialização de produtos e da prestação de serviços farmacêuticos em farmácias e drogarias e dá outras providências. Diário Oficial da União, Brasília, DF, I8 ago.2009. Seção I, p. 78$8 \mathrm{I}$.

BRASIL. Lei no 5.991,de 17 de dezembro de 1973. Dispõe sobre o controle sanit' rio do comércio sanitário de drogas, medicamentos, insumos farmacêuticos e correlatos, e dá outras providências. Diário Oficial da União, Brasília, DF, ig dez.1973,p.13049.

BRASIL, Ministério da Educação, Resolução CNE/CES no 2, de I9 de fevereiro de 2002. Institui as Diretrizes Curriculares Nacionais do Curso de Graduação em Farmácia. Diário Oficial da União, Brasília, DF., 4 mar.2002. Seção ı,p.9.

BASTOS, C. R. G.; CAETANO, R. As percepções dos farmacêuticos sobres seus trabalhos na farmácia comunitárias em uma região do estado do Rio de Janeiro. Ciência \& Saúde Coletiva, Rio de Janeiro, v.15,p.354I-3550,2010. Suplemento 3.

BRANDÃO, A. Farmácias: uma abordagem sanitária. Conselho Federal de Farmácia, Brasília, DF,21 jan.2014. Notícias do CFF. Disponível em: HTTPS://goo.gl/fH9seh. Acesso em :31 out. 2017.

CARNEIRO, C. Farmácia de oficina: projeções para o futuro. OFFARM, Barcelona,v.5,n.56,p.40-42,1998.

CFF- CONSELHO FEDERL DE FARMÁCIA . Resolução no 357, de 20 de abril de 200I. Aprova o regulamento técnico das Boas Práticas em Farmácia. Diário Oficial da União, Brasília, DF, 27 abr.2001. Seção I,p.24-30.

CFF- CONSELHO FEDERAL DE FARMÁCIA. Resolução n] 585, de 29 de agosto de 2013. Regulamenta as atribuições clínicas do farmacêutico e dá outras providências. Diário Oficial da União, Brasília, DF, 25 set 2013b.Seção I,p.i86. 
CFF - CONSELHO FEDERAL DE FARMÁCIA. Resolução no 586, de 29 de agosto de 2013. Regula a prescrição farmacêutica e dá outras providências. Diário Oficial da União, Brasília, DF, 26 de set.2013c. Seção i,p.136.

CONFERENNCIA NACIONAL DE MEDICMENTOS E ASSISTÊNCIA FARMACÊUTICA, I., 2005, Brasília, DF. Relatório final: efetivando o acesso, a qualidade e a humanização na assistência farmacêutica, com controle social. Brasília, DF: Ministério da Saúde, 2005.(Série D. Reuniões e conferências).

ESHER,A.; COUTINHO,T. Uso racional de medicamentos, farmaceuticalização e usos do metilfenidato. Ciência e Saúde Coletiva, Rio de Janeiro,v.22,n. 8,p.25712580,2017 .

FARINA, S. S.: ROMANO-LIEBER, N.S. Atenção farmacêutica em farmácias e drogarias: existe um processo de mudança? Saúde e sociedade, São Paulo,v.ı,n.ı,p.718,2009 .

MINAYO,M.C.S. O desafio do conhecimento: pesquisa qualitativa em saúde. São Paulo: Hucitec, 2004.

OLIVEIRA, A.B. ET AL. Obstáculos da atenção farmacêutica no Brasil. Revista Brasileira de Ciências Farmacêuticas, São Paulo, v.4I,n.4,p.409-413,2005.

OPAS - ORGANIZAÇÃO PAN-AMERICANA DE SAÚDE. Conselho Brasileiro de Atenção Farmacêutica: proposta. Brasília, DF,2002.

SANTOS,A.M. Desafios e oportunidades do farmacêutico na promoção da saúde. Infarma, Brasília, DF, v.17, n.5/6,p.73-78,2005.

SILVA, L. R.; VIEIRA, E.M. Conhecimento dos farmacêuticos sobre legislação sanitária e regulamentação da profissão. Revista de Saúde Pública. Sõ Paulo,v.38n.3,p.429-437,2004.

SERAFIN,C.; CORREIA JÚNIOR, D.; VARGAS, M. Perfil do farmacêutico no Brasil: relatório. Brasília, DF: Conselho Federal de Farmácia, 2015.

VIEIRA ,F.S. Possibilidades de contribuição do farmacâutico para a promoção da saúde. Ciência \&Saúde Coletiva, Rio de Janeiro,v.12,n.I,p.213-220,2007. 